\title{
Light up the embryos: knock-in reporter generation for mouse developmental biology
}

\author{
$\operatorname{Bin} \mathrm{Gu}^{1,2,3 *}$ (D) \\ ${ }^{1}$ Program in Developmental and Stem Cell Biology, Hospital for Sick Children, Toronto, Canada \\ ${ }^{2}$ Department of Obstetrics, Gynecology and Reproductive Biology, College of Human Medicine, Michigan State University, \\ Michigan, USA \\ ${ }^{3}$ Institute for Quantitative Health Science and Engineering, Michigan State University, Michigan, USA
}

How to cite: Gu B. Light up the embryos: knock-in reporter generation for mouse developmental biology. Anim Reprod. 2020;17(3):e20200055. https://doi.org/10.1590/1984-3143-AR2020-0055

\begin{abstract}
Developmental biology seeks to understand the sophisticated regulated process through which a single cell - a fertilized egg - generates a highly organized organism. The most effective way to reveal the nature of these processes is to follow single cells and cell lineages in real-time. Recent advances in imaging equipment, fluorescent tags and computational tools have made long term multi-color imaging of cells and embryos possible. However, there is still one major challenging for achieving live imaging of mammalian embryos- the generation of embryos carrying reporters that recapitulate the endogenous expression pattern of marker genes. Recent developments of genome editing technology played important roles in enabling efficient generation of reporter mouse models. This mini review discusses recent developments of technologies for efficiently generate knock-in reporter mice and the application of these models in live imaging development. With these developments, we are starting to realize the long-sought promises of realtime analysis of mammalian development.
\end{abstract}

Keywords: CRISPR-Cas9, genome editing, knock-in reporter, HDR, embryo.

\section{Main text}

'Seeing is believing.' There is nothing more convincing in developmental biology than a movie that reveal the progress of embryonic development in realtime, such as this one showed here (movie 1). This movie captures the process when a mouse preimplantation embryo develops from a 16-cell embryo to a blastocyst with a frame captured every 20 minutes. Two cell lineages were marked by distinctive fluorescent reporters of lineage marker genes, Cdx2-eGFP (in green) for trophectoderm(TE) and Halo-Sox2 (in red) for inner cell mass(ICM). As you can see, the movie captured many critical processes including, the morphogenetic transition from a solid spherical morula to a blastocyst that contains a central cavity-blastocoel, and the sequential emergence of $C d \times 2$ positive TE and Sox 2 positive ICM cells. You can even tell that the Sox 2 positive cells emerge roughly 9 hours after the $C d \times 2$ positive cells from the time stamps. With this level of spatio-temporal resolution, developmental biology is entering an exciting time. A few technological advancements are required for developmental biology to enter the live imaging time: First, fluorescent tag proteins need to be developed for visualizing a biological entity such as protein, RNA or DNA in living embryos. There are indeed major advancements recently on this line. A large variety of fluorescent proteins, self-labelling tags and bridging molecules has allowed the visualization of almost any molecular entity of the Central Dogma in living embryos by fluorescent imaging spanning a broad optical spectrum - from blue to infra-red (Tsien, 1998; Bindels et al., 2017;

*Corresponding author: bin.gu@sickkids.ca; gubin1@msu.edu

Received: May 15, 2020. Accepted: June 26, 2020.

Financial support: None.

Conflicts of interest: The authors have no conflict of interest to declare. 
Shcherbakova et al., 2015; Los et al., 2008; Kolberg et al., 2013; Rodriguez et al., 2007; Tanenbaum et al., 2014). Second, new microscopes such as light-sheet microscopy and multiphoton microscopy, which significantly decrease photo-toxicity during imaging, have created unprecedented possibilities for long-term live imaging of embryonic development (Benninger et al., 2008; Wan et al., 2019). Third, advanced computational tools are needed and have been developed to extract biological relevant information from large imaging datasets (Amat et al., 2015). However, with of all these advancements, the first challenge we need to overcome for realizing all the promises of studying development in realtime, is still to obtain the embryo that carry the specific fluorescent reporters. It is actually quite challenging to obtain these reporter embryos in an efficient and scalable manner, especially for mammalian species such as mouse. This minireview will focus on the recent developments in the gene editing technology, including some of our own experiences, in efficiently generating knock-in reporter mouse models for live imaging research. This is not meant to be an exhaustive review of literature in knock-in technology, instead I will use a few approaches that have been relatively broadly implemented to illustrate the principles behind the new knock-in technologies to generate reporters. I regret not being able to discuss numerous interesting technology developments in this field.

Scientists have been generating reporter mice for a long time, mostly using two classical technologies. The first one is random transgenesis. In this case, protein dynamics were investigated through the use of fluorescent proteins driven by partial regulatory sequences such as promoter or enhancer regions of a gene-of-interest (Ikawa et al., 1998). These reporter constructs are integrated randomly into the mouse genome through pronuclear microinjection- a relatively fast process more amenable for large scale production (Ittner and Gotz, 2007). This approach has been instrumental in revealing gene expression patterns in live embryos. However, random transgenesis has intrinsic drawbacks. For example, random transgenic reporters frequently fail to recapitulate gene expression patterns due to the lack of full regulatory sequences. Also, the effects of local chromatin environment of the particular insertion site contribute to the expression variability between lines carrying the same transgene (Palmiter et al., 1983; Laboulaye et al., 2018; Weis et al., 1992). Moreover, recent efforts of mapping the insertion locus of a large number of established transgenic mouse lines has identified numerous accompanying complex genomic changes in addition to the transgene insertion. Such changes include large insertions or deletions at the insertion site, which could lead to confounding phenotypes unrelated to the particular transgene (Goodwin et al., 2019). Knock-in, defined as the precise insertion of an exogenous sequence into an endogenous genomic locus, could largely resolve these drawbacks and achieve faithful tagging of endogenous genes. Traditionally, knock-in mouse embryonic stem(ES) cells are first generated through homologous recombination mediated gene targeting, which typically has a low success frequency. Then these knock-in ES cells are aggregated with or injected into wildtype mouse preimplantation embryos to establish chimeric founders. Only when the knock-in ES cells contributed to the germline of the chimeric founders, knock-in mouse lines can be established. Therefore, it typically requires the screening of hundreds of ES cell clones, which is followed by time consuming chimera generation and breeding (Thomas and Capecchi, 1987; Capecchi, 2005). It is apparent that neither of these technologies would be sufficient for the precision and scalability of reporter generation if we are going to realize the promising of live imaging in developmental biology.

New genome editing technologies, most notably the CRISPR/Cas9 system, have completely changed the landscape in gene editing (Hsu et al., 2014). Particularly, it allowed targeted gene editing directly through micro-injecting into early embryos by targeted introduction of double strand breaks at desired genomic locus, which bypasses the typically tedious and time-consuming cell engineering steps (Yang et al., 2013). CRISPR/Cas9 zygote injection has been proved to be highly efficient in generating knock-out alleles through non-homologous end join(NHEJ) pathway, as well as generating point mutation and small tag insertions through homology directed repair(HDR) (Yang et al., 2013). These approaches have brought new hope for rapidly generating reporter embryos. However, although with initial promising reports, the efficiency of HDR mediated large fragment knock-in, which is required for inserting most fluorescent tags, through mouse 
zygote injection tends to be variable and not robust (Yang et al., 2013; Cohen, 2016). A few recently developed technologies have improved the efficiency of reporter mice generation.

The first was a technology called Efficient $a$ dditions with ssDNA inserts-CRISPR (Easi-CRISPR) (Quadros et al., 2017). Instead of double-stranded plasmid DNA that were traditional used for gene targeting, Easi-CRISPR uses long single-stranded DNA as donor templates (Quadros et al., 2017; Miura et al., 2018). By microinjection of ribonucleoprotein complexes of Cas9 protein bound with a complexed crRNA and tracrRNA guide alongside a long sSDNA template encoding the desired knock-in sequence flanked by 60 to 105 base homology arms, Easi-CRISPR was used to accomplish knock-in of fragments varying from 800 base pairs to 1.4 kilobase pairs with efficiencies ranging from 25-67\% (Quadros et al., 2017). However, at present, long single-stranded DNA template synthesis remains a primary limitation of Easi-CRISPR, with insertion of fragments greater than 1-2 kilobases remaining a challenge. Furthermore, it has been observed that the secondary structure that may be formed within a long single-stranded DNA molecule could lead to the skipping of donor sequences during repair (Codner et al., 2018). This poses another challenge for precise knock-in using Easi-CRISPR.

A crucial technological advancement - two-cell homologous recombination (2C-HR)-CRISPR - was provided by our group based on insights from the understanding of mouse early embryonic development (Gu et al., 2018). It is well-established that HDR is predominantly active in the late S-G2 phases of the cell cycle (Hustedt and Durocher, 2016). Indeed, there had been numerous reports that timing genome editing to coincide with this period in vitro could lead to significantly greater frequency of editing events mediated by HDR (Yang et al., 2016; Lin et al., 2014). We reasoned that the two-cell stage mouse embryo, which have an exceptionally long G2 phase (10-12 hours), might permit higher knock-in efficiency. Furthermore, the accessible chromatin state during zygotic genome activation, which occurs during the elongated G2 phase of two-cell embryos, could also contribute to efficient knock-in (Svoboda, 2018). Indeed, in a side-by-side experiment, delivery of the editing components to a two-cell stage embryo resulted in a significant enhancement of knock-in efficiency compared to zygotes, increasing the efficiency from $1-5 \%$ to $30-35 \%$ at the two loci tested. Among many gene locus, 2C-HR-CRISPR allowed for the knock-in of reporter alleles in up to $60 \%$ of founder mice - simply by changing the timing of delivery. Importantly, 2C-HR-CRISPR was shown to be highly efficient in spite of knock-in size and was used to introduce fragments as large as 7.5 kilobases. To further improve 2C-HR-CRISPR, we modified the system once further. There are speculations that HDR is hindered by the search for homologous sequences following the introduction of a DSB (Ma et al., 2017). Therefore, recruiting the donor template to the DSB-site might increase the efficiency of HDR. One efficient method to recruit DNA template to a Cas9 induced DSB is through the biotin-avidin interaction. Therefore, we constructed a Cas9-monomeric streptavidin(mSA) fusion gene. By co-injecting Cas9-mSA mRNA, sgRNA and a biotinylated PCR product as repair template, the repair template would bind to the Cas9-mSA protein and be recruited to the proximity of the double strand break and improve the knock-in efficiency. With this modification, the 2C-HR-CRISPR system produced knock-in efficiencies of up to $95 \%$ in some genes at the founder mouse stage (e.g., Gata6-Halo reporter gene) and high germline transmission - with some targets reaching $100 \%$. Using 2C-HR-CRISPR, we have generated 35 knock-in reporters for critical developmental regulators, and moving forward to understand the developmental dynamics of mouse embryonic development. Some of these mouse models have been used to dissect the cell migration process in mouse gastrulation and the mechanical controls of mouse early limb development (McDole et al., 2018; Zhu et al., 2020).

While the techniques described above can reliably mediate large-fragment knock-in, in each case, their successful implementation all require micro-injection gene editing reagents into mouse early embryos. The technical challenges of micro-injection pose significant hurdle for their broad application. Recently, multiple groups have developed injection-free knock-in methods by delivering gene editing reagents using adeno-associated viral vectors into mouse zygotes (Chen et al., 2019; Yoon et al., 2018, Mizuno et al., 2018). A common theme of these techniques is the delivery of donor templates using AAV vectors, while the Cas9 and sgRNA are delivered either as AAV vectors or as Cas9-sgRNA complex (RNPs). These technologies have been shown to generate knock-in reporters with high efficiency $(50 \%)$, therefore, greatly 
simplified the process of generating knock-in reporter mice. However, size of the knock-in cassette is limited by the packaging capability of AAV vector(4.9kb).

Other HDR independent technologies such as the micro-homology mediated end joining (MMEJ) mediated CRISPR/Cas9-based precise integration into the targeted chromosome (CRIS-PITCh) and homology mediated end joining (HMEJ) based methods has also been developed to generate knock-in reporters in a wide range of organisms (Nakade et al., 2014; Yao et al., 2017). These technologies as well hold great potential in generating knock-in reporter mice, although they are right now less used in mouse genetics, probably because the HDR based methods, that typically enable more sequence precision, are sufficiently efficient for mouse generation.

With these exciting technology developments, we are already seeing a number of reported studies dissecting mouse embryonic development using live imaging. With more and more knock-in reporters generated and characterized, we will enter a bright future of mammalian developmental biology.

\section{References}

Amat F, Hockendorf B, Wan Y, Lemon WC, McDole K, Keller PJ. Efficient processing and analysis of largescale light-sheet microscopy data. Nat Protoc. 2015;10(11):1679-96. http://dx.doi.org/10.1038/nprot.2015.111. PMid:26426501.

Benninger RK, Hao M, Piston DW. Multi-photon excitation imaging of dynamic processes in living cells and tissues. Rev Physiol Biochem Pharmacol. 2008;160:71-92. http://dx.doi.org/10.1007/112_2008_801. PMid:18418560.

Bindels DS, Haarbosch L, van Weeren L, Postma M, Wiese KE, Mastop M, Aumonier S, Gotthard G, Royant A, Hink MA, Gadella TW Jr. mScarlet: a bright monomeric red fluorescent protein for cellular imaging. Nat Methods. 2017;14(1):53-6. http://dx.doi.org/10.1038/nmeth.4074. PMid:27869816.

Capecchi MR. Gene targeting in mice: functional analysis of the mammalian genome for the twenty-first century. Nat Rev Genet. 2005;6(6):507-12. http://dx.doi.org/10.1038/nrg1619. PMid:15931173.

Chen S, Sun S, Moonen D, Lee C, Lee AY, Schaffer DV, He L. CRISPR-READI: efficient generation of knockin mice by CRISPR RNP electroporation and AAV Donor infection. Cell Rep. 2019;27(13):3780-9.e4. https://doi.org/10.1016/j.celrep.2019.05.103.

Codner GF, Mianne J, Caulder A, Loeffler J, Fell R, King R, Allan AJ, Mackenzie M, Pike FJ, McCabe CV, Christou S, Joynson S, Hutchison M, Stewart ME, Kumar S, Simon MM, Agius L, Anstee QM, Volynski KE, Kullmann DM, Wells S, Teboul L. Application of long single-stranded DNA donors in genome editing: generation and validation of mouse mutants. BMC Biol. 2018;16(1):70. http://dx.doi.org/10.1186/s12915-018-0530-7. PMid:29925374.

Cohen J. 'Any idiot can do it.' Genome editor CRISPR could put mutant mice in everyone's reach. Science. 2016:89407621. http://dx.doi.org/10.1126/science.aal0334.

Goodwin LO, Splinter E, Davis TL, Urban R, He H, Braun RE, Chesler EJ, Kumar V, van Min M, Ndukum J, Philip VM, Reinholdt LG, Svenson K, White JK, Sasner M, Lutz C, Murray SA. Large-scale discovery of mouse transgenic integration sites reveals frequent structural variation and insertional mutagenesis. Genome Res. 2019;29(3):494-505. http://dx.doi.org/10.1101/gr.233866.117. PMid:30659012.

Gu B, Posfai E, Rossant J. Efficient generation of targeted large insertions by microinjection into two-cellstage mouse embryos. Nat Biotechnol. 2018;36(7):632-7. http://dx.doi.org/10.1038/nbt.4166. PMid:29889212.

Hsu PD, Lander ES, Zhang F. Development and applications of CRISPR-Cas9 for genome engineering. Cell. 2014;157(6):1262-78. http://dx.doi.org/10.1016/j.cell.2014.05.010. PMid:24906146.

Hustedt N, Durocher D. The control of DNA repair by the cell cycle. Nat Cell Biol. 2016;19(1):1-9. http://dx.doi.org/10.1038/ncb3452. PMid:28008184.

Ikawa M, Yamada S, Nakanishi T, Okabe M. 'Green mice' and their potential usage in biological research. FEBS Lett. 1998;430(1-2):83-7. http://dx.doi.org/10.1016/S0014-5793(98)00593-6. PMid:9678599.

Ittner LM, Gotz J. Pronuclear injection for the production of transgenic mice. Nat Protoc. 2007;2(5):120615. http://dx.doi.org/10.1038/nprot.2007.145. PMid:17546016.

Kolberg K, Puettmann C, Pardo A, Fitting J, Barth S. SNAP-tag technology: a general introduction. Curr Pharm Des. 2013;19(30):5406-13. http://dx.doi.org/10.2174/13816128113199990514. PMid:23431982. 
Laboulaye MA, Duan X, Qiao M, Whitney IE, Sanes JR. Mapping Transgene Insertion Sites Reveals Complex Interactions Between Mouse Transgenes and Neighboring Endogenous Genes. Front Mol Neurosci. 2018;11:385. http://dx.doi.org/10.3389/fnmol.2018.00385. PMid:30405348.

Lin S, Staahl BT, Alla RK, Doudna JA. Enhanced homology-directed human genome engineering by controlled timing of CRISPR/Cas9 delivery. eLife. 2014;3:e04766. http://dx.doi.org/10.7554/eLife.04766. PMid:25497837.

Los GV, Encell LP, McDougall MG, Hartzell DD, Karassina N, Zimprich C, Wood MG, Learish R, Ohana RF, Urh M, Simpson D, Mendez J, Zimmerman K, Otto P, Vidugiris G, Zhu J, Darzins A, Klaubert DH, Bulleit RF, Wood KV. HaloTag: a novel protein labeling technology for cell imaging and protein analysis. ACS Chem Biol. 2008;3(6):373-82. http://dx.doi.org/10.1021/cb800025k. PMid:18533659.

Ma M, Zhuang F, Hu X, Wang B, Wen XZ, Ji JF, Xi JJ. Efficient generation of mice carrying homozygous double-floxp alleles using the Cas9-Avidin/Biotin-donor DNA system. Cell Res. 2017;27(4):578-81. http://dx.doi.org/10.1038/cr.2017.29. PMid:28266543.

McDole K, Guignard L, Amat F, Berger A, Malandain G, Royer LA, Turaga SC, Branson K, Keller PJ. In Toto Imaging and reconstruction of post-implantation mouse development at the single-cell level. Cell. 2018;175(3):859-76.e33. https://doi.org/10.1016/j.cell.2018.09.031.

Miura H, Quadros RM, Gurumurthy CB, Ohtsuka M. Easi-CRISPR for creating knock-in and conditional knockout mouse models using long ssDNA donors. Nat Protoc. 2018;13(1):195-215. http://dx.doi.org/10.1038/nprot.2017.153. PMid:29266098.

Mizuno N, Mizutani E, Sato H, Kasai M, Ogawa A, Suchy F, Yamaguchi T, Nakauchi H. Intra-embryo gene cassette knockin by CRISPR/Cas9-mediated genome editing with adeno-associated viral vector. iScience. 2018;9:286-97. https://doi.org/10.1016/j.isci.2018.10.030.

Nakade S, Tsubota T, Sakane Y, Kume S, Sakamoto N, Obara M, Daimon T, Sezutsu H, Yamamoto T, Sakuma T, Suzuki KT. Microhomology-mediated end-joining-dependent integration of donor DNA in cells and animals using TALENs and CRISPR/Cas9. Nat Commun. 2014;5(1):5560. http://dx.doi.org/10.1038/ncomms6560. PMid:25410609.

Palmiter RD, Norstedt G, Gelinas RE, Hammer RE, Brinster RL. Metallothionein-human GH fusion genes stimulate growth of mice. Science. 1983;222(4625):809-14. http://dx.doi.org/10.1126/science.6356363. PMid:6356363.

Quadros RM, Miura H, Harms DW, Akatsuka H, Sato T, Aida T, Redder R, Richardson GP, Inagaki Y, Sakai D, Buckley SM, Seshacharyulu P, Batra SK, Behlke MA, Zeiner SA, Jacobi AM, Izu Y, Thoreson WB, Urness LD, Mansour SL, Ohtsuka M, Gurumurthy CB. Easi-CRISPR: a robust method for one-step generation of mice carrying conditional and insertion alleles using long SSDNA donors and CRISPR ribonucleoproteins. Genome Biol. 2017;18(1):92. http://dx.doi.org/10.1186/s13059-017-1220-4. PMid:28511701.

Rodriguez AJ, Condeelis J, Singer RH, Dictenberg JB. Imaging mRNA movement from transcription sites to translation sites. Semin Cell Dev Biol. 2007;18(2):202-8. http://dx.doi.org/10.1016/j.semcdb.2007.02.002. PMid:17376719.

Shcherbakova DM, Baloban M, Verkhusha VV. Near-infrared fluorescent proteins engineered from bacterial phytochromes. Curr Opin Chem Biol. 2015;27:52-63. http://dx.doi.org/10.1016/j.cbpa.2015.06.005. PMid:26115447.

Svoboda P. Mammalian zygotic genome activation. Semin Cell Dev Biol. 2018;84:118-26. http://dx.doi.org/10.1016/j.semcdb.2017.12.006. PMid:29233752.

Tanenbaum ME, Gilbert LA, Qi LS, Weissman JS, Vale RD. A protein-tagging system for signal amplification in gene expression and fluorescence imaging. Cell. 2014;159(3):635-46. http://dx.doi.org/10.1016/j.cell.2014.09.039. PMid:25307933.

Thomas KR, Capecchi MR. Site-directed mutagenesis by gene targeting in mouse embryo-derived stem cells. Cell. 1987;51(3):503-12. http://dx.doi.org/10.1016/0092-8674(87)90646-5. PMid:2822260.

Tsien RY. The green fluorescent protein. Annu Rev Biochem. 1998;67(1):509-44. http://dx.doi.org/10.1146/annurev.biochem.67.1.509. PMid:9759496.

Wan Y, McDole K, Keller PJ. Light-sheet microscopy and its potential for understanding developmental processes. Annu Rev Cell Dev Biol. 2019;35(1):655-81. http://dx.doi.org/10.1146/annurev-cellbio100818-125311. PMid:31299171.

Weis J, Fine SM, Sanes JR. Integration site-dependent transgene expression used to mark subpopulations of cells in vivo: an example from the neuromuscular junction. Brain Pathol. 1992;2(1):31-7. PMid:1341945. 
Yang D, Scavuzzo MA, Chmielowiec J, Sharp R, Bajic A, Borowiak M. Enrichment of G2/M cell cycle phase in human pluripotent stem cells enhances HDR-mediated gene repair with customizable endonucleases. Sci Rep. 2016;6(1):21264. http://dx.doi.org/10.1038/srep21264. PMid:26887909.

Yang $\mathrm{H}$, Wang $\mathrm{H}$, Shivalila CS, Cheng AW, Shi L, Jaenisch R. One-step generation of mice carrying reporter and conditional alleles by CRISPR/Cas-mediated genome engineering. Cell. 2013;154(6):1370-9. http://dx.doi.org/10.1016/j.cell.2013.08.022. PMid:23992847.

Yao X, Wang X, Hu X, Liu Z, Liu J, Zhou H, Shen X, Wei Y, Huang Z, Ying W, Wang Y, Nie YH, Zhang CC, Li S, Cheng L, Wang Q, Wu Y, Huang P, Sun Q, Shi L, Yang H. Homology-mediated end joining-based targeted integration using CRISPR/Cas9. Cell Res. 2017;27(6):801-14. http://dx.doi.org/10.1038/cr.2017.76. PMid:28524166.

Yoon Y, Wang D, Tai PWL, Riley J, Gao G, Rivera-Perez JA. Streamlined ex vivo and in vivo genome editing in mouse embryos using recombinant adeno-associated viruses. Nat Commun. 2018;9(1):412. http://dx.doi.org/10.1038/s41467-017-02706-7. PMid:29379011.

Zhu M, Tao H, Samani M, Luo M, Wang X, Hopyan S, Sun Y. Spatial mapping of tissue properties in vivo reveals a 3D stiffness gradient in the mouse limb bud. Proc Natl Acad Sci USA. 2020;117(9):4781-91. http://dx.doi.org/10.1073/pnas.1912656117. PMid:32071242. 
ERRATUM

\section{ERRATUM}

In the article entitle "Light up the embryos: knock-in reporter generation for mouse developmental biology", DOI number: https://doi.org/10.1590/1984-3143-AR2020-0055, published in journal Animal Reproduction, 2020, volume 17, number 3, page 1:

Where it reads:

"Thematic Section: 36th Annual Meeting of the Association of Embryo Technology in Europe $(\mathrm{AETE})$ "

It should read:

"Thematic Section: 34th Annual Meeting of the Brazilian Embryo Technology Society (SBTE)" 